\title{
Phytoremediation of domestic wastewaters in free water surface constructed wetlands using Azolla pinnata
}

\begin{abstract}
Two constructed wetlands, one with Azolla pinnata plant (CW1) and the other without (CW2) for treating domestic wastewaters were developed. Fifteen water parameters which include: Dissolved Oxygen (DO), Biochemical Oxygen Demand (BOD5), Chemical Oxygen Demand (COD), Total Suspended Solid (TSS), Total Phosphorus (TP), Total Nitrogen (TN), Ammoniacal Nitrogen (NH3N), Turbidity, pH, Electrical Conductivity (EC), Iron (Fe), Magnesium (Mg), Manganese (Mn), and heavy metals such as Lead ( $\mathrm{Pb}$ ) and Zinc ( $\mathrm{Zn}$ ) were analyzed using standard laboratory procedures. The experiments were conducted in two (dry and wet) seasons simultaneously. Results showed considerable reductions in all parameters and metals including $\mathrm{Zn}$ in CW1 compared with $\mathrm{CW} 2$ in the two seasons considered while $\mathrm{Pb}$ and $\mathrm{Mn}$ were not detected throughout the study. Zn concentration levels reduced significantly in both seasons just as removal efficiencies of $70.03 \%$ and $64.51 \%$ were recorded for CW1 while $35.17 \%$ and $33.45 \%$ were recorded for CW2 in both seasons. There were no significant differences in the removal efficiencies of Fe in both seasons as $99.55 \%, 59.09 \%, 88.89 \%$, and $53.56 \%$ were recorded in CW1 and CW2 respectively. Azolla pinnata has proved effective in domestic wastewater phytoremediation studies.
\end{abstract}

Keyword: Azolla pinnata; Constructed wetlands; Phytoremediation; Removal efficiency; Wastewater 